\title{
International trade and investment: still the foundation for tackling nutrition related non-communicable diseases in the era of Trump?
}

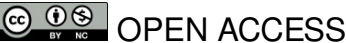 \\ Trade and investment policy strongly influence diet, nutrition, and risk of non-communicable \\ disease-but what does this mean in the context of recent global political developments?
}

\section{Helen Walls assistant professor ${ }^{1}$, Richard Smith deputy pro-vice chancellor and professor ${ }^{2}$, Soledad Cuevas research fellow ${ }^{3}$, Johanna Hanefeld associate professor ${ }^{1}$}

${ }^{1}$ Faculty of Public Health and Policy, London School of Hygiene and Tropical Medicine, UK; ${ }^{2}$ University of Exeter, UK; ${ }^{3}$ SOAS University of London, UK

\section{Key messages}

The 2030 Agenda for Sustainable Development identified international trade as a structural driver of sustainable development, including identification of the risk posed by international trade to the prevalence of non-communicable disease (NCD)

- Poor diet and nutrition are risk factors for NCDs, accounting for $40 \%$ of annual deaths from NCDs

- Trade and investment policy impact diet and nutrition through the food system and by affecting domestic policy and regulatory space relating to nutrition

We outline key pathways of this trade-nutrition impact on nutrition related NCD risk and consider their implications in the context of an evolving global trade regime

Non-communicable diseases (NCDs) constitute half the global burden of disease, ${ }^{1}$ and are associated with high health, social, and economic costs. ${ }^{2}$ The 2030 Agenda for Sustainable Development, adopted in 2015, recognised NCDs as a major challenge for sustainable development—and identified international trade as an important structural driver.

Trade and investment are associated with potential benefits to health. ${ }^{45}$ However, since the 2008 food crisis-which saw a surge in international cereal prices-and in the context of the growing global prevalence of obesity, the possible harmful impacts of trade on diet and nutrition have gained attention from researchers and policy makers. ${ }^{6}$

Poor diet and nutrition are strongly linked to NCD risk, accounting for around $40 \%$ of annual deaths from NCDs. ${ }^{78}$ Trade and investment agreements and policies influence diet through their impact on local food environments-including price, availability, composition, and promotion. ${ }^{9}$ This impact results from changes relating particularly to the import and export of agricultural and food products, foreign direct investment, and the effects on domestic policy. ${ }^{610}$
The evolving international trade regime has taken a recent turn, however, as seen in the current nationalist rhetoric evident in many countries but signified especially by the UK vote to leave the European Union ${ }^{11}$ and the election of Donald Trump to the US presidency - one of whose first actions was to withdraw the country from the Trans Pacific Partnership Agreement. The trend of past years towards increasing trade liberalisation may therefore be at an end-and with it, concerns for nutrition related health problems.

International politics and changes to global trading relationships pose unpredictability. Trade is unlikely to contract, however, and its impact on health will remain critical to analyse. We draw on existing literature to discuss three key pathways of the impact of trade and investment on nutrition and NCDs-and consider the implications of the evolving international trade regime.

\section{Impacts through food imports and exports}

Global markets encourage countries to specialise in particular agricultural and food production for export, including "cash crops" (crops grown for profit, such as wheat). This increases global output of such products. ${ }^{6}$ Countries can use imports to increase access to a greater variety of foods, such as tropical fruits during winter; this leads to greater homogenisation of food availability. ${ }^{12}$ The health impacts are dependent largely on the mix of foods (healthy and unhealthy) a country trades.

Exporting primary produce, such as unprocessed fruits and vegetables, can negatively impact domestic food consumption if affected farmers might otherwise have grown food for a country's own use. The promotion of crop exports can lead to increases in prices in local markets and have detrimental effects on local food security (such as quinoa in Bolivia ${ }^{13}$ and teff, the staple grain of Ethiopia ${ }^{14}$ ). Several studies suggest, however, a larger share of land devoted to cash crops improves child nutrition through better incomes for farmers - at least when 
certain conditions are met regarding women's roles in household decision making. ${ }^{1516}$

For the importing country, nutritional impacts largely depend on the nutritional quality of the products imported.

Unfortunately, foods with the longest shelf lives and those most easily traded and stored are "ultra-processed" foods-those that are generally more energy dense and higher in fats, sugars, and salt. They have a commercial advantage over fresh, perishable products, and are associated with overweight and obesity and NCDs. ${ }^{17}$

Evidence is mixed regarding the impact of food imports on nutrition and NCDs. A number of studies suggest positive outcomes, such as improved dietary quality, food security, and reductions in underweight in low and middle income countries (LMICs). An analysis of 30 LMICs, for example, found no evidence of significant associations between more tariffs (taxes applied to imports and exports) and mean body mass index (BMI), although they did suggest higher tariffs were associated with lower BMI for poorer, rural populations. ${ }^{6}$

While current trade conflicts between the US and China, for example, are likely to affect overall volume of trade growth, ${ }^{18}$ it is unlikely that the overall trend, including in foodstuffs, will be significantly affected or reversed. This is further evidenced by the Trans Pacific Partnership proceeding, despite US withdrawal. Thus, the patterns of health impact through food import and export will likely remain.

\section{Impacts through foreign direct investment}

Foreign direct investment (FDI) is controlling ownership in a business in one country by an entity based in another. FDI provides opportunities for companies to enter new markets for processed foods, advertise and market their products more efficiently, and create demand for their products while adapting to local consumer characteristics. It is thought that FDI, not trade, is the preferred method for transnational food and beverage companies, such as Pepsico and Unilever, and retailers, such as Carrefour and KFC, to enter new markets. ${ }^{6}$

Several studies have found FDI to be an increasingly important driver of ultra-processed food consumption, and increases in overweight and obesity, particularly in LMICs. ${ }^{6}$ Increases in soft drink consumption in Mexico after increases in food imports and FDI by US firms, following the North American Free Trade Agreement in 1994, have been clearly documented. By 2010, Mexico had the highest consumption of soft drinks globally: 300 L per capita annually. ${ }^{1920}$ Similarly, studies have found significant increases in per capita soft drink consumption attributable to removal of FDI restrictions in Vietnam and Peru. ${ }^{6}$

The public discourse around globalisation has changed in recent years, and Trump, for example, campaigned on an explicit anti-globalisation platform. In 2017, global FDI dropped by $16 \%$. This, however, was largely because of a decline in FDI in the UK and US, while it remained stable in LMICs. ${ }^{21}$ It is mainly in LMICs that the FDI-diet relationship has been observed-likely because high income countries already have high levels of ultra-processed foods.

\section{Impacts on policy and regulatory space for tackling nutrition goals}

The World Trade Organisation (WTO) is the international body responsible for global trade rules between countries, but since the 1990s an increasing number of regional and bilateral trade and investment agreements have been negotiated outside its system (see box). These new trade and investment agreements have problematic implications for domestic policy making. ${ }^{22}$ Especially concerning is the inclusion of the "investor-state dispute settlement mechanism," through which companies can directly sue states if governments implement regulation that might lead to reduced profits. ${ }^{24}$

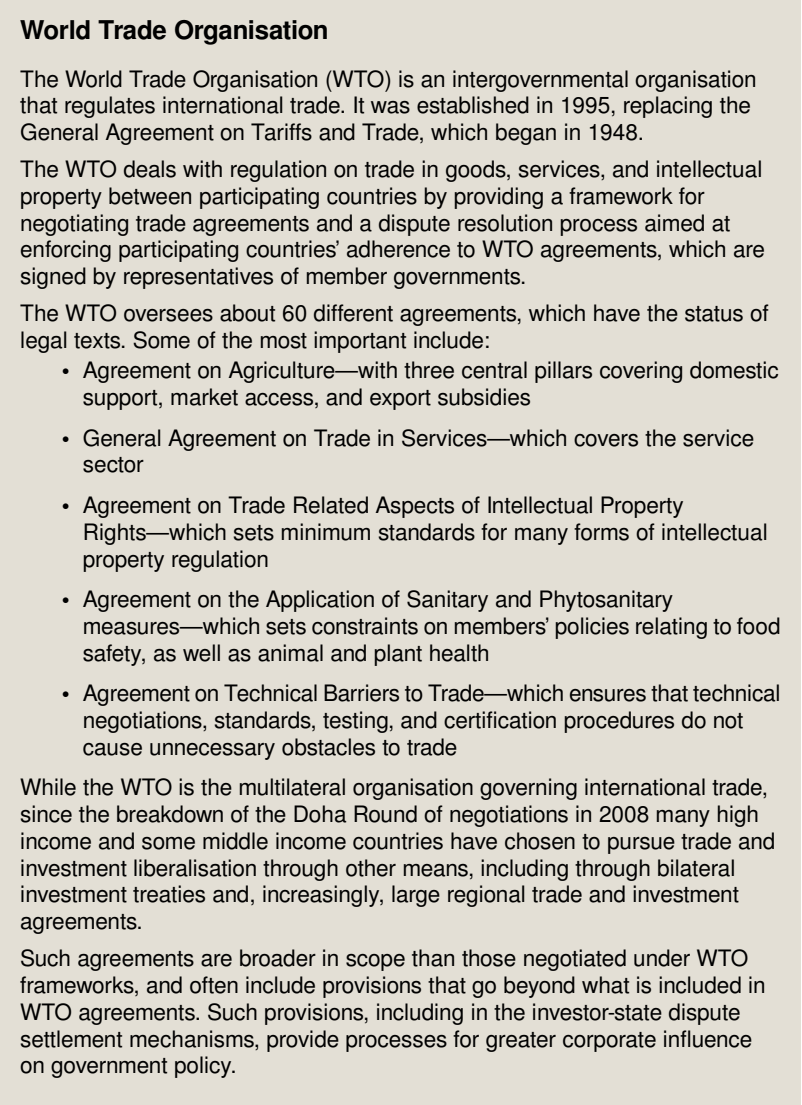

Under these new generation agreements there have been legal challenges to domestic policy affecting tobacco control (as well as through WTO mechanisms). ${ }^{25}$ Tobacco control shows how trade and investment agreements have been used to increase corporate influence, and serves as an example of risks to nutrition policy. In 2011, Phillip Morris Asia challenged the Australian government's plain tobacco packaging policy, based on a foreign investment protection provision in a 1993 bilateral investment treaty between Australia and Hong Kong. While the tobacco company failed in its bid to overturn Australian tobacco laws (2017), some authors have noted the risk of such foreign investment provisions to nutrition policy: ${ }^{26}$ the implementation of domestic sugar taxes, for example, could be threatened by such provisions.

However, WTO mechanisms, such as the Technical Barriers to Trade Committee meetings, are also concerning for nutrition policymaking. Specific trade concerns have been raised at these meetings regarding nutrition labelling initiatives in Chile,

Ecuador, Indonesia, Peru, and Thailand. ${ }^{27}$ Questions were asked about the justification of proposed labelling measures, their consistency with international standards, and the evidence of their effectiveness. Such developments may weaken nutrition policy initiatives-in Thailand, after several WTO member states raised concerns about Thai food policy, a "children should take less" message and a traffic light system (showing sugar, fat, salt, and energy content) was abandoned in favour of a food labelling system preferred by industry. ${ }^{28}$ Such challenges to domestic policy also result in "policy chill," with regulations less likely to be initiated in countries elsewhere. ${ }^{29}$ 
Some countries have developed nutrition policy that is compliant with trade commitments. Ghana's policy to tackle the trade in fatty meat, a standard applied to imported and domestic meat, is one example. ${ }^{30}$ Another is Samoa reversing its 2007 ban on turkey tails (a fatty meat) as part of its accession to the WTO in 2011, and subsequently developing a trade compliant nutrition policy. ${ }^{31}$ The WTO working party overseeing Samoa's accession raised two concerns about the ban-these related to its effectiveness in tackling diets and NCDs, and the principle of non-discrimination between imported and domestic foods, given that many high fat foods were still available for purchase in Samoa. After removing the ban and acceding to the WTO, Samoa undertook a study of its policy options and in 2016 implemented a nutrition policy compliant with its trade commitments. ${ }^{31}$

The effects of trade and investment agreements on state regulatory and policy space is less obvious and harder to tackle than other problems-and yet it limits governments' ability to tackle increasing rates of NCD, including in regard to nutrition. Again, much like the direct impact on overall levels of trade or FDI, it seems unlikely this trend will dramatically change. The progression of the Trans Pacific Partnership Agreement certainly suggests so.

\section{Discussion and conclusion}

Tackling the unfolding NCD crisis means tackling trade and investment policy, as it plays an important role in shaping diet and nutrition globally. While the current trade regime may be evolving into something new, analysis of past trade-nutrition relationships suggests various impact pathways. In particular, trade openness appears to have contributed to shifts in dietary patterns, and FDI is most strongly associated with increases in obesity and NCDs.

While policymakers can exert control over FDI and transnational food companies by setting standards for processing, labelling, packaging, and retailing, large investor companies can be difficult to control after they enter a market, with regulation required at many points, from processing to packaging, advertising, and distribution. ${ }^{22}{ }^{32}$ Some commentators have argued that the establishment of large companies constrains domestic policy space for tackling poor nutrition through lobbying and relocation threats. ${ }^{33}$

Domestic nutrition labelling policies have sometimes been influenced by WTO concerns. However, with the types of provisions often included in regional or bilateral trade and investment agreements, there is now scope for countries to be sued by corporations for domestic policymaking in regard to nutrition. Exceptions in some cases negotiated for tackling tobacco control should be extended to nutrition. There is, however, further scope for development of trade policy coherent with nutritional goals, with an important role for governments. In addition to the scope for countries to develop nutrition policy compliant with trade commitments using import barriers, governments can use domestic policies to improve local food environments (such as availability and access, prices, and affordability), although dietary quality of foods available also requires consideration. ${ }^{34}$ Given the high burden of malnutrition and NCDs globally, there is a critical need for further policy initiatives to tackle trade, diets, and nutrition.

We may be entering a new era in trade and health; a change that will undoubtedly provide opportunities and risks for nutrition and NCDs. If current trends continue, there is likely to be further rises in overweight and obesity and NCDs. The specifics of current changes are not able to be foreseen, however, and monitoring and analysis of trade-health relationships will remain important, as will the public health community's awareness of the role that trade plays in shaping nutrition and rates of NCDs. Despite increasing isolationist rhetoric by some leaders, trade will likely continue and will remain fundamental to diets and nutrition. It is important that the public health community does not allow this rhetoric to detract attention from the importance of trade for nutrition, especially the importance of changes to bilateral trade and investment agreements and away from trading blocs (such as Brexit and the decline of the WTO). Such changes, in fact, provide greater imperative for public health community involvement in matters of trade and health.

Competing interests: We have read and understood BMJ policy on declaration of interests and declare that we have no competing interests.

Contributor statement: The first author and last author conceived of the article. The first author led the writing of the manuscript. All authors contributed to critical content and reviewed drafts of the manuscript.

1 Benziger CP, Roth GA, Moran AE. The global burden of disease study and the preventable burden of NCD. Glob Heart 2016;11:393-7. 10.1016/j.gheart.2016.10.024 27938824

2 Bonita R, Magnusson R, Bovet P, et alLancet NCD Action Group. Country actions to meet UN commitments on non-communicable diseases: a stepwise approach. Lancet 2013;381:575-84. 10.1016/S0140-6736(12)61993-X 23410607

3 United Nations. Transforming our world: the 2030 Agenda for Sustainable Development. 2015. https://sustainabledevelopment.un.org.

4 Gomes L. The economics and ideology of free trade: an historical review. Edward Elgar Publishing, 200310.4337/9781781950272.

5 Dollar D, Kraay A. Growth is good for the poor. World Bank, 2002

6 Cuevas García-Dorado S, Cornselsen L, Smith R, Walls H. Economic globalization, nutrition and health: a review of quantitative evidence. Global Health 2019;15:15 10.1186/s12992-019-0456-z 30786909

7 Beaglehole R, Bonita R, Horton R, et alLancet NCD Action GroupNCD Alliance. Priority actions for the non-communicable disease crisis. Lancet 2011;377:1438-47. actions for the non-communicable disease crisis.

8 World Health Organization. Risk factor estimates for 2004. 2017. www.who.int/healthinfo/ global_burden_disease/risk_factors/en.

9 Turner C, Kadiyala S, Aggarwal A, et al. Concepts and methods for food environment research in low and middle income countries. Agriculture, Nutrition, and Health Academy. 2017. https://anh-academy.org/food-environments-technical-brief.

10 Friel S, Hattersley L, Snowdon W, et allNFORMAS. Monitoring the impacts of trade agreements on food environments. Obes Rev 2013;14(Suppl 1):120-34. 10.1111/obr.12081 24074216

11 Stuckler $D$. The dispossessed: a public health response to the rise of the far-right in Europe and North America. Eur J Public Health 2017;27:5-6. 10.1093/eurpub/ckw244 28177453

12 Khoury CK, Bjorkman AD, Dempewolf $\mathrm{H}$, et al. Increasing homogeneity in global food supplies and the implications for food security. Proc Natl Acad Sci USA 2014;111:4001-6. 10.1073/pnas.131349011124591623

13 Brett J. The political-economics of developing markets versus satisfying food needs. Food Foodways 2010;18:28-4210.1080/07409711003708249.

14 Secorun L. Teff could be the next quinoa as Ethiopia boosts exports. 2016. www. theguardian.com/sustainable-business/2016/oct/14/teff-quinoa-ethiopia-boosts-exportsfood-africa.

15 Kennedy E. Household food security and child nutrition: the interaction of income and gender of household head. World Dev 1992;20:1077-8510.1016/0305-750X(92)90001-C.

16 Kennedy $\mathrm{E}$, Bouis $\mathrm{H}$, von Braun J. Health and nutrition effects of cash crop production in developing countries: a comparative analysis. Soc Sci Med 1992;35:689-97. 10.1016/0277-9536(92)90007-D 1439919

17 Moodie R, Stuckler D, Monteiro C, et alLancet NCD Action Group. Profits and pandemics: prevention of harmful effects of tobacco, alcohol, and ultra-processed food and drink industries. Lancet 2013;381:670-9. 10.1016/S0140-6736(12)62089-3 23410611

18 IMF. World economic outlook update July 2018. 2018. www.imf.org/en/Publications/WEO/ Issues/2018/07/02/world-economic-outlook-update-july-2018.

19 Stuckler D, McKee M, Ebrahim S, Basu S. Manufacturing epidemics: the role of global producers in increased consumption of unhealthy commodities including processed foods, alcohol, and tobacco. PLoS Med 2012;9:e1001235. 10.1371/journal.pmed.1001235 22745605

20 Clark SE, Hawkes C, Murphy SME, Hansen-Kuhn KA, Wallinga D. Exporting obesity: US farm and trade policy and the transformation of the Mexican consumer food environment. Int J Occup Environ Health 2012;18:53-64. 10.1179/1077352512Z.0000000007 22550697

21 UNCTAD. Investment Trend Monitor January 2018. UNCTAD; 2018. https://unctad.org/ en/pages/publications/Global-Investment-Trends-Monitor-(Series).aspx.

22 Walls HL, Smith RD, Drahos P. Improving regulatory capacity to manage risks associated with trade agreements. Global Health 2015;11:14. 10.1186/s12992-015-0099-7 25890343

23 Gleeson D, Friel S. Emerging threats to public health from regional trade agreements. Lancet 2013:381:1507-9. 10.1016/S0140-6736(13)60312-8 23453142

24 Baker $\mathrm{P}$, Kay A, Walls $\mathrm{H}$. Trade and investment liberalization and Asia's noncommunicable disease epidemic: a synthesis of data and existing literature. Global Health 2014;10:66.25213212

25 Gleeson DH, Tienhaara KS, Faunce TA. Challenges to Australia's national health policy from trade and investment agreements. Med J Aust 2012;196:354-6. 10.5694/mja11.11635 22432677

26 Walls H, Hanefeld J, Smith RD. The Trans-Pacific Partnership: should we 'fear the fear'? Int $\checkmark$ Health Policy Manag 2017;6(6):353-5. 
27 Thow AM, Jones A, Hawkes C, Ali I, Labonté R. Nutrition labelling is a trade policy issue: lessons from an analysis of specific trade concerns at the World Trade Organization. Health Promot Int 2018;33:561-71.28082373

28 Walls $\mathrm{H}$, Baker P, Smith R. Commentary: Moving towards policy coherence in trade and health. J Public Health Policy 2015;36:491-501. 10.1057/jphp.2015.23 26245251

29 Tienhaara K. Regulatory chill and the threat of arbitration: a view from political science. Brown C MK, ed. Cambridge University Press, 2011.

30 Thow AM, Annan R, Mensah L, Chowdhury SN. Development, implementation and outcome of standards to restrict fatty meat in the food supply and prevent NCDs: learning from an innovative trade/food policy in Ghana. BMC Public Health 2014;14:249. 10.1186/1471-2458-14-249 24625217

31 Thow AM, Reeve E, Naseri T, Martyn T, Bollars C. Food supply, nutrition and trade policy: reversal of an import ban on turkey tails. Bull World Health Organ 2017;95:723-5. 10.2471/BLT.17.192468 29147046

32 Maestre M, Poole N, Henson S. Assessing food value chain pathways, linkages and impacts for better nutrition of vulnerable groups. Food Policy 2017;68:31-910.1016/j.foodpol.2016.12.007.
33 Brownell KD, Warner KE. The perils of ignoring history: Big Tobacco played dirty and millions died. How similar is Big Food? Milbank Q 2009;87:259-94. 10.1111/j.1468-0009.2009.00555.x 19298423

34 Ickowitz A, Powell B, Rowland D, Jones A, Sunderland T. Agricultural intensification dietary diversity, and markets in the global food security narrative. Glob Food Secur 2019;20:9-1610.1016/j.gfs.2018.11.002.

Published by the BMJ Publishing Group Limited. For permission to use (where not already granted under a licence) please go to http:/group.bmj.com/group/rights-licensing/ permissionsThis is an Open Access article distributed in accordance with the Creative Commons Attribution Non Commercial (CC BY-NC 4.0) license, which permits others to distribute, remix, adapt, build upon this work non-commercially, and license their derivative works on different terms, provided the original work is properly cited and the use is non-commercial. See: http://creativecommons.org/licenses/by-nc/4.0/ 